\title{
DIAGNÓSTICO RÁPIDO E DIALOGADO EM ESTUDOS DE DESENVOLVIMENTO RURAL SUSTENTÁVEL ${ }^{1}$
}

\author{
ALFREDO JOSÉ BARRETO LUIZ² e MIGUEL ÂNGELO DA SILVEIRA ${ }^{3}$
}

\begin{abstract}
RESUMO - O principal objetivo deste trabalho foi verificar se a suposição de predominância da agricultura familiar na microbacia do Taquara Branca, Sumaré, SP, poderia ser sustentada com base em informações concretas. Foi possível a utilização de amostragem probabilística, pois estava disponível um mapa com os limites das 106 propriedades da microbacia, sendo sorteadas 33 delas para a aplicação de questionários do tipo cross-section. A técnica multivariada empregada foi a análise de agrupamentos, para a qual foi utilizado o procedimento PROC CLUSTER do SAS. Nessa análise só foram considerados os dados referentes aos 22 respondentes que exerciam atividade agrícola. Após a análise unidimensional, algumas perguntas foram selecionadas com base na variabilidade entre as respostas e, a partir destas, construíram-se as variáveis necessárias para se proceder à análise multidimensional. A análise de agrupamento permitiu identificar claramente três grupos naturais entre as 22 propriedades. De acordo com as características dos componentes de cada grupo, foi possível classificá-los em: grupo 1, doze propriedades de agricultura familiar; grupo 2, seis propriedades de agricultura não familiar em pequenas áreas; e grupo 3, quatro propriedades de agricultura não familiar em grandes áreas. Embora não seja predominante (apenas 36\%), a agricultura familiar é o grupo mais freqüente na microbacia do Taquara Branca.
\end{abstract}

Termos para indexação: agricultura familiar, análise de agrupamentos, amostragem.

\section{RAPID RURAL AND DIALOGED APPRAISAL FOR SUSTAINABLE RURAL DEVELOPMENT}

ABSTRACT - The main objective of this research was to test the hypothesis of whether family agriculture, as defined herewith, would indeed be predominant in the Taquara Branca watershed, in the State of São Paulo, Brazil, site of a larger sustainable development assessment study. Data on 33 of 106 landholdings in the watershed were obtained by directly applied cross-section questionnaires. The variables for multivariate analysis were first selected through a unidimensional analysis, when some questions were selected with basis on answer variability. Multivariate statistics was used (PROC CLUSTER, SAS) to define and analyze the groupings. Twenty two respondents (out of the 33) were involved in agricultural activities, comprising, then, the universe of the study. Cluster analysis allowed the identification of three natural groups among the 22 landholdings. It was possible to classify each group, according to their characteristics, as follows: group 1 - twelve typical family landholdings; group 2 - six non-family, small landholdings; and group 3 - four non-family, large landholdings. Although not predominant in terms of area, typical family agriculture was found to be the more frequent $(36 \%)$ in the watershed.

Index terms: family agriculture, cluster analysis, sampling

\section{INTRODUÇÃO}

Parece haver um consenso, entre pesquisadores e técnicos, em considerar o importante papel que a

\footnotetext{
${ }^{1}$ Aceito para publicação em 25 de março de 1999.

${ }^{2}$ Eng. Agrôn., M.Sc., Embrapa-Centro Nacional de Pesquisa de Monitoramento e Avaliação de Impacto Ambiental (CNPMA), Caixa Postal 69, CEP 13820-000 Jaguariúna, SP. E-mail: alfredo@cnpma.embrapa.br

${ }^{3}$ Rel. Púb., Dr., Embrapa-CNPMA.
}

unidade de análise microbacia desempenha no contexto das pesquisas sobre impactos ambientais causados pelas práticas agrícolas. Apesar desse entendimento, os limites e as possibilidades a propósito de avaliar a unidade microbacia como um referencial analítico de excelência, ainda não se esgotaram.

Contudo, essa discussão se torna mais complexa quando o foco é centrado em sistemas agrícolas praticados por produtores familiares. Isso porque os estudos que optam pela unidade microbacia hidrográfica têm-se restringido ao plano ambiental, 
no seu sentido mais restrito, "numa ótica que ignora a determinação dos atores principais dos processos de produção do meio ambiente: os seres humanos, ou o conjunto das relações sociais através das quais eles se apropriam da natureza" (Silveira, 1998b).

O presente texto retoma, aqui, para todos os que lidam com a problemática da agricultura familiar e sustentabilidade, um dos desafios metodológicos enfrentados pela equipe de pesquisadores do projeto Avaliação Socioambiental de Impactos e Agricultura Familiar. O caráter interdisciplinar dessa pesquisa enfoca a agricultura familiar distintamente de investigações que têm a perspectiva da neutralidade técnica e a transferência tecnológica como trilhas dominantes (Busch et al., 1989). Por isso mesmo, conta, em retorno, com os métodos qualitativos da Sociologia, da Antropologia, e com os instrumentos de pesquisa da Estatística, incorporados aos das ciências naturais. A descrição do citado desafio destaca particularmente o importante papel cumprido, uma vez mais, pela Estatística em atividades interdisciplinares de pesquisa agropecuária.

Espera-se que desse exercício resultem algumas contribuições significativas, não apenas para futuros trabalhos, mas também para o desenvolvimento da reflexão sobre metodologia de avaliação de impactos ambientais, tema de interesse central na Embrapa-Centro Nacional de Pesquisa de Monitoramento e Avaliação de Impacto Ambiental (CNPMA).

No estágio inicial da elaboração do diagnóstico agroambiental realizado na microbacia hidrográfica do córrego Taquara Branca (MTB), em Sumaré, SP, os membros da equipe de pesquisa notaram a possível existência de unidades de produção familiares integradas ao capital comercial, principalmente por meio do cultivo de hortaliças, cafeicultura e, mesmo, produção de leite, e de lavouras com o propósito de autoconsumo.

A intenção daquele projeto de pesquisa era levantar e analisar a relação existente entre os impactos ambientais e a agricultura praticada pelos produtores rurais familiares da MTB, bem como os do Assentamento Rural I, inserido na área, tendo-se em vista uma intervenção em conjunto com os mesmos. O Assentamento Rural I de Sumaré foi instalado na MTB no começo do ano de 1984, como decorrência de uma forte pressão exercida por um grupo de famílias durante 1983. Esse grupo organizou-se com apoio da comunidade eclesial de base da Igreja Nossa Senhora de Fátima, no bairro de Rosolém, na própria cidade de Sumaré, antes mesmo de o Movimento dos Trabalhadores Sem Terra - MST - organizar-se em âmbito nacional. Apesar da familiaridade com o MST (também organizou-se a partir da influência da chamada ala progressista da Igreja Católica) o movimento surge relativamente isolado de outros movimentos similares.

Para que fosse possível aprofundar e hierarquizar as informações sobre a heterogeneidade e o modo de gestão da produção familiar, em termos de integração com o mercado, forma de acesso à terra e à tecnologia, localização, tipo e formas de cultivo, entre outras, foi necessário, em primeiro lugar, identificar a existência ou persistência das unidades de agricultura familiar na MTB.

Assim, como objetivo principal deste trabalho, optou-se por verificar se a suposta predominância da agricultura familiar na área podia ser sustentada com base em informações concretas, coletadas por meio de questionários simples aplicados aos produtores. A forma escolhida para a obtenção dos dados foi a execução de um diagnóstico rápido dialogado como primeiro passo de uma proposta metodológica, o que é comum em pesquisas onde a necessidade básica é o conhecimento da realidade na qual se insere o produtor (Gastal et al., 1993). Como objetivo secundário, pretendeu-se demonstrar a validade dos métodos utilizados para a coleta e para o tratamento dos dados.

\section{Mudança rural, agricultura familiar e sustentabilidade}

Do ponto de vista das ciências sociais, o processo de transformação capitalista da agricultura no Brasil, por demais estudado, tem como conseqüências mais visíveis, por um lado, o aumento da produtividade e da eficiência, integração crescente aos capitais industrial, financeiro e comercial, e o estabelecimento dos complexos agroindustriais, entre outros (Silva, 1982; Martine, 1989). Por outro lado, provocou a extrema concentração fundiária, o êxodo rural, o inchaço de cidades, o surgimento de trabalho do bóia-fria e o estabelecimento da monocultura, 
determinada e determinante de todas essa condições. Pode também ser considerado como responsável pela profunda mudança nas bases técnicas, no processo de trabalho e na distribuição dos recursos materiais ocorridos no setor.

A modernização da agricultura brasileira estabeleceu uma invasão de insumos e equipamentos que atendiam aos interesses industriais, e que também eram demandados por agricultores com algum grau de capitalização. Em conseqüência, provocou uma inversão na racionalidade tecnológica da agricultura tradicional capaz de modernizar-se, bem como a determinação de novos padrões de troca, na direção das necessidades da indústria processadora de produtos agrícolas, ou seja, a adesão à lógica do mercado.

A pequena produção familiar, nesse contexto, inseriu-se de maneira parcial: parte dela foi eliminada e compôs a mão-de-obra urbana e os volantes rurais, e outra parte passou por uma modernização intermediária. Exatamente por isso, vive uma condição de insuficiência econômica, estando quase sempre no limite da sobrevivência. O restrito poder de barganha da agricultura familiar no contexto político mais amplo não permitiu até hoje uma ruptura na direção de sua autonomia.

De qualquer modo, alguns autores (Reinhardt \& Barlett, 1989; Veiga, 1991; Lamarche, 1993) afirmam que apesar da contínua diminuição na participação da população economicamente ativa na agricultura capitalista a partir do anos 1960, a agricultura familiar persiste e não constitui uma categoria em extinção. Para confirmar, Kageyama \& Bergamasco (1991) davam conta da existência, no Estado de São Paulo, de 148.927 (54,5\%) unidades de produção de base familiar. O espaço ocupado representava $29 \%$ da área total cadastrada, e a participação dessas unidades no total da produção agropecuária era de $35 \%$. Contavam com $43,5 \%$ da frota de tratores, e constituíam $48,5 \%$ do total de mão-de-obra estadual.

A opção pela pesquisa junto a esses produtores, entretanto, se justifica também como ação estratégica. A estrutura fundiária brasileira apresenta elevado grau de concentração da propriedade e da posse da terra (índices de Gini entre 0,90 e 0,95 - numa escala onde o máximo é igual a 1,00 - o que indica concentrações quase absolutas) (Sampaio, 1988).
Entretanto, a maior parte da mão-de-obra empregada e da produção obtida pela agricultura está localizada em propriedades de até 100 ha (Lorena, 1989). Esses dados foram confirmados em FAO (1994).

Ademais, a agricultura familiar é um importante componente do sistema de produção agrícola brasileiro, tanto no que diz respeito ao abastecimento interno e para exportação, quanto para a manutenção da oferta de ocupação e emprego rural. Um bom exemplo é a comparação proposta, também pelo relatório da FAO (1994), entre estabelecimentos familiares do estrato de área de $20 \mathrm{a} 100$ ha que ocupam apenas 58 milhões de hectares, em contraste com os patronais de estrato de área de 500 a 10.000 ha, com cerca de 150 milhões de hectares ocupados. O segmento patronal é superado pelo familiar em 15 produtos importantes: carnes suínas e de aves, leite, ovos, batata, trigo, cacau, banana, café, milho, feijão, algodão, tomate, mandioca e laranja. Quanto à oferta de carne bovina, cana-de-açúcar, arroz e soja, a agricultura patronal apresenta rendimentos superiores.

Dentro da tendência atual da "nascente ecologização da agricultura" (Buttel, 1995) ou ainda, em um contexto de constituição de novas relações de trabalho no meio rural (Silva, 1997), a agricultura familiar representa a alternativa possível de garantir as fontes de biodiversidade e incrementar a sustentabilidade. Isso se dá porque o modelo baseado na produção familiar tende a utilizar de forma mais racional os insumos externos e por isso é o que melhor atende às pressões sociais, que têm aumentado no mundo inteiro, no sentido de uma maior preservação do ambiente (Pinheiro, 1992).

A dinâmica da agricultura familiar, com uma racionalidade econômica diferente da do capitalista e do camponês quanto às decisões de produção e de investimento (Munguia Payés \& Silveira, 1997), tem como principais características o "trabalho e a gestão relacionados intimamente; direção do processo produtivo assegurada diretamente pelos proprietários; ênfase na diversificação; ênfase na durabilidade dos recursos naturais e na qualidade da vida; trabalho assalariado complementar; decisões imediatas, adequadas ao alto grau de imprevisibilidade do processo produtivo; tomada de decisões in loco, condicionada pelas especificidades do processo pro- 
dutivo; ênfase no uso de insumos internos" (FAO, 1994).

Ademais, segundo Canuto et al. (1994), a agricultura familiar compreende sistemas de amplitude variável, que têm a família como referencial econômico e sociocultural; engloba sistemas camponeses e sistemas de pequena agricultura parcialmente modernizada.

A essas características, soma-se o fato de a agricultura familiar ter, no que diz respeito aos recursos naturais, a perspectiva da preservação voltada para o futuro e não para a próxima safra e, em contraste com o paradigma técnico-científico homogeneizante da monocultura, intimamente relacionado a uma série de danos ambientais, o conhecimento da operação de sistemas diversificados.

Para Mussoi (1997), a diversificação produtiva, própria da agricultura familiar, lhe garante o autoconsumo e a integração com o mercado em condições de manter "níveis adequados de biodiversidade (produtiva, medicinal, artesanal e de reserva biológica), sendo capaz de processar muitos dos produtos por ela produzidos e reciclar dejetos para sua reutilização".

Como contraponto, contudo, existem autores que defendem a idéia de que "por disporem de poucos recursos materiais e tecnológicos, o segmento de subsistência da agricultura familiar cria e perpetua um ciclo de degradação $\rightarrow$ baixa produtividade $\rightarrow$ pobreza $\rightarrow$ poucos recursos $\rightarrow$ mais degradação" (Lal, 1994). Portanto, a relação entre a agricultura familiar e a degradação ambiental precisa ser alvo de estudos profundos, que visem qualificar e quantificar os impactos ambientais, positivos ou negativos, desse tipo de atividade.

\section{MATERIAL E MÉTODOS}

\section{A área do estudo}

A área do estudo, a microbacia do córrego Taquara Branca, abrange 2.700 hectares, sendo $85 \%$ em Sumaré e 15\% em Hortolândia, SP, caraterizando-se como área de agricultura diversificada (Otani et al.,1995). As atividades agrícolas mais importantes são a olericultura e as culturas de tomate, batata, cana-de-açúcar, feijão, milho, mandioca e café. As atividades de pecuária se caracterizam pela criação de gado de leite e de corte (Kitamura et al., 1999).

Outras características importantes da área da microbacia, além do conjunto de 26 famílias que forma o Assentamento Fundiário I, são a existência de três glebas de extração de terra para olarias, dois bairros residenciais, e chácaras de lazer. Na microbacia do córrego Taquara Branca também se localiza, vizinha ao assentamento, a Represa do Horto com 19,5 km² de área de drenagem, construída em 1988, e tendo por contribuintes os córregos Taquara Branca e Bassos. A represa é a principal fonte de abastecimento de água das cidades de Sumaré e de Hortolândia, atendendo a uma população estimada em 250 mil pessoas (Silveira, 1998b).

A ocupação do solo da Taquara Branca parecia indicar "uma predominância do modelo baseado na agricultura familiar" (Bazin, 1994), que seria responsável por uma parte significativa da produção agrícola, bem como pela composição da mão-de-obra.

Os múltiplos usos do solo dessa microbacia (agricultura, mineração e residencial), associados à inadequação de tecnologias utilizadas, vêm acarretando impactos ambientais expressivos, refletindo-se principalmente na erosão do solo e na qualidade e quantidade de água da Represa do Horto e de seus afluentes (Kitamura et al., 1999).

$\mathrm{Na}$ agricultura, o uso intensivo de máquinas e implementos agrícolas, o desmatamento, a eliminação da matéria orgânica do solo (queima de restos culturais), manejo inadequado de pastagens (ausência de calagem e adubação, divisão incorreta dos pastos e localização dos cochos de sal e bebedouros), plantio sucessivo de culturas anuais intensivas e utilização de sistemas de irrigação por aspersão e por sulco (grande escorrimento superficial da água sem captação do excedente), enfim, ausência de práticas conservacionistas, vêm acarretando a perda de fertilidade e erosão do solo (Kitamura et al., 1999).

As perdas de solo ocasionadas pelas práticas agrícolas, estradas rurais mal dimensionadas e sem conservação, além das áreas de movimento de terra, provocam grande deslocamento de sedimentos para o fundo dos córregos e Represa do Horto. Estudos feitos pela CETESB (1991) comprovam as modificações ocorridas no leito da represa, fator que compromete a capacidade de armazenamento e diminui a expectativa de sua vida útil.

Como o consumo de água para a irrigação na Taquara Branca durante o ano todo é alto, os agricultores também têm observado os riscos da falta de água, principalmente nas lavouras plantadas nos meses mais secos do ano (junho a agosto, chegando, em 1994, a cerca 120 dias sem chuva). Nesse período, os reservatórios de captação redu- 
zem-se a níveis críticos, causando racionamento de água (Silveira, 1998b).

Além da redução da quantidade disponível, já se faz sentir a queda na qualidade da água captada para usos urbanos. O sistema de filtro lento instalado na Represa do Horto está dimensionado para processar água de boa qualidade, separando apenas macroelementos. Em razão da elevada presença de partículas de solo, a filtragem não tem sido satisfatória, com muitas reclamações da população quanto a cor e sabor da água consumida (Silveira, 1998b).

A relevância da microbacia pode ser ressaltada em função do significativo uso de agrotóxicos em culturas de expressão como a do tomate e a da batata. Além do risco de contaminação dos recursos hídricos, observa-se, a despeito do crescente uso desses produtos, o aumento contínuo da incidência de pragas e doenças, conseqüência da falta de critério na utilização desses insumos. Não existe, por parte da maioria dos aplicadores de agrotóxicos, a consciência dos riscos à saúde, que a manipulação desses produtos pode causar. Trabalham, via de regra, sem a utilização de equipamentos de proteção individual (Silveira, 1998a).

A estrutura fundiária da Taquara Branca é bastante concentrada, e grande parte dos produtores tem pequenos lotes. Associada à expansão da urbanização, apresentam sistemas de produção que em sua maioria "guardam certa dependência externa (crédito rural, mercados de insumos e produtos, assistência técnica, etc.), mas com a produção agrícola, mesmo que para venda, ainda voltada basicamente para a reprodução familiar” (Kitamura et al., 1999).

\section{Coleta e análise de dados}

Os dados foram coletados através da aplicação de 33 questionários do tipo cross-section, distribuídos de forma aleatória entre as propriedades da MTB. Os questionários foram aplicados por pessoal treinado, em um único dia de maio de 1996. O questionário aplicado continha apenas oito perguntas, quase totalmente fechadas, a maioria com respostas numéricas, o que permitiu que o tempo médio para o seu preenchimento fosse de 20 minutos.

É importante ressaltar que neste trabalho, diferentemente de outros (Santana \& Khan, 1990; Souza Neto et al., 1995), foi possível a utilização de amostragem probabilística, pois estava disponível um mapa com os limites de todas as propriedades da microbacia (Fig. 1).

De posse desse mapa, foi atribuído um número a cada propriedade e, através do uso da função geradora de números aleatórios RANUNI do SAS (SAS, 1988), foram sorteadas 32 delas, o que corresponde a $30 \%$ do total de 106 propriedades da MTB. Como uma das propriedades escolhidas estava arrendada para dois agricultores, constituindo duas unidades de produção distintas, o questionário foi desmembrado, produzindo um total de 33 respondentes.

Para a análise de dados obtidos através de questionários que avaliam características socioeconômicas, alguns autores preferem se utilizar apenas de análises unidimensionais (Otani et al., 1995, 1996); outros, aplicam apenas análises multidimensionais (Angelo et al., 1990), e há ainda os que preferem utilizar os dois tipos de análise simultaneamente (Molina Filho, 1976; Souza Neto et al., 1995). Pelas características dos dados e dos objetivos deste trabalho, também aqui optou-se pelo uso das duas abordagens, ou seja: primeiramente, foram explorados os dados, mediante a análise unidimensional, e a seguir, utilizaram-se técnicas de análise multivariada.

A análise univariada, nesse caso, é extremamente simples, e consiste na tabulação, em separado, das respostas a

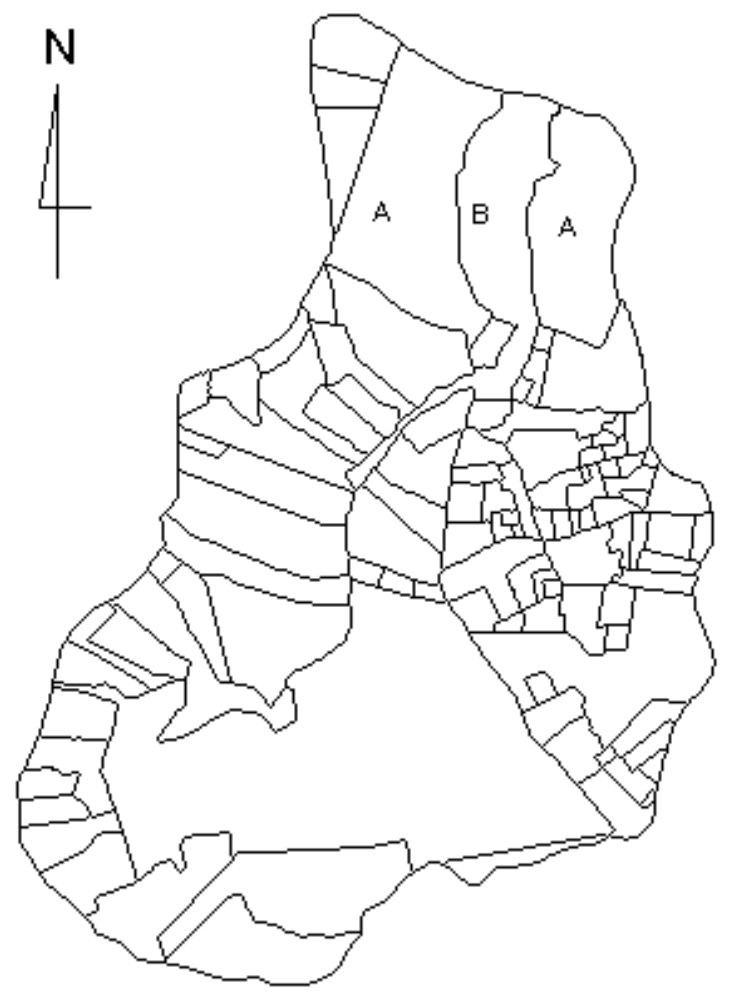

FIG. 1. Distribuição espacial das propriedades, área de assentamento rural (A) e barragem (B), na microbacia do Córrego Taquara Branca, em Sumaré, SP.

Pesq. agropec. bras., Brasília, v.35, n.1, p.83-91, jan. 2000 
cada pergunta. Os resultados são apresentados em números absolutos (no caso da quantidade de cabeças animais por unidade de produção, por exemplo), ou em percentuais.

A técnica multivariada utilizada foi a análise de agrupamentos (cluster analysis), para a qual foi empregado o procedimento PROC CLUSTER do SAS (SAS, 1988). Nessa análise só foram contabilizados os dados referentes aos 22 respondentes que possuíam atividade agrícola. Após a análise unidimensional, algumas perguntas foram selecionadas com base na variabilidade entre as respostas, e a partir destas respostas, foram construídas as variáveis necessárias para se proceder à análise multidimensional (Judez Asensio, 1988).

As variáveis utilizadas foram as seguintes: compvend $=$ se o entrevistado decide sobre a compra de insumos e sobre a venda da produção, então essa variável assume o valor 1 . Senão, ela vale 0 (zero);

numcult $=$ número de culturas na área;

numespan = número de espécies animais na área;

trabcont $=$ porcentagem do trabalho contratado,

se $0 \%$ a variável vale 4

se $>0$ e $<30 \%$ a variável vale 3

se $\geq 30$ e $\leq 70 \%$ a variável vale 2

se $>70$ e $<100 \%$ a variável vale 1

se $100 \%$ a variável vale 0 ;

sucessor $=$ se o respondente disse que terá um sucessor, a variável vale 1 . Senão, ela vale 0 ;

renda $=$ se mais da metade da renda vem da lavoura ou da criação, a variável vale 1 . Senão, ela vale 0 ;

área $=$ área da propriedade,

se $\leq 7$ ha a variável vale 4

se $>7$ e $\leq 14$ ha a variável vale 3

se $>14$ e $\leq 28$ ha a variável vale 2

se $>28$ e $\leq 56$ ha a variável vale 1

se $\geq 56$ ha a variável vale 0 .

O objetivo da análise de agrupamentos foi o de verificar a existência de grupos naturais entre os respondentes e, na existência deles, identificar suas características.

\section{RESULTADOS E DISCUSSÃO}

Das 33 propriedades amostradas, onze não desenvolviam atividade agrícola, dez delas se destinavam às atividades de lazer ou só residência, e uma estava abandonada, sem construções nem cultura ou criação.

Nas 22 restantes, a maioria absoluta (18) dos questionários foi respondida por pessoas que afirmavam serem os responsáveis pela decisão quanto à compra de insumos e à venda da produção. Apenas dois não eram os responsáveis diretos por essa atividade, e outros dois não responderam a questão.

As atividades agrícolas presentes no total das propriedades eram compostas por 178,8 ha de pastagem, 60 ha de banana, 36,3 ha de caqui, 35,7 ha de hortaliças, 14,6 ha de milho, 8,4 ha de feijão, 7,2 ha de eucalipto, 4,8 ha de tomate, 4,4 ha de mandioca, 3,5 ha de café, 3,4 ha de arroz, 2,4 ha de cana e 1,5 ha de acerola, além de uma área de 2,4 ha utilizada para confinamento de gado bovino. Metade das propriedades (11) possuía uma única cultura, já o número de áreas com duas, três ou quatro atividades agrícolas era de 6, 3 e 2, respectivamente.

Quanto à criação de animais, 14 propriedades possuíam, no total, 184 bovinos de corte, 115 bovinos de leite, 14 equinos, 110 aves e 16 suínos. A quantidade de áreas onde se criavam uma, duas, três e quatro espécies era de sete, quatro, duas e uma, respectivamente.

$\mathrm{O}$ trabalho ligado às atividades agrícolas em apenas duas propriedades era totalmente $(100 \%)$ realizado por pessoal contratado; em outras seis, esse percentual era inferior a 100 , mas superior a $70 \%$; em sete delas era menor que $30 \%$, e em cinco áreas, nenhum $(0 \%)$ trabalho era contratado, e todo ele era realizado pelo agricultor e sua família. Dois entrevistados não responderam a esse item. Do que era contratado, metade constituía-se de trabalho assalariado; $28 \%$, de diaristas; $11 \%$, de empreitada; e $11 \%$, de percenteiros.

Com relação à continuidade das atividades agrícolas por um sucessor da própria família, metade (11) dos respondentes acredita nessa possibilidade, enquanto apenas quatro a descartam; outros sete entrevistados não sabiam ou não responderam à questão.

Na Tabela 1, aparece o número de respondentes por categoria de proveniência da renda anual total, e na Tabela 2, consta a quantidade de possuidores de cada tipo de equipamento utilizado nas atividades agrícolas. Dois entrevistados não responderam a essas perguntas.

A análise de agrupamento permitiu identificar claramente três grupos naturais entre as 22 propriedades com atividade agrícola. Após a verificação das características dos componentes de cada grupo, é possível classificá-los da seguinte maneira: 
Grupo 1 = agricultura familiar;

Grupo 2 = agricultura não familiar em pequenas áreas;

Grupo 3 = agricultura não familiar em grandes áreas.

O grupo 1, formado por doze propriedades, se caracteriza por ter todos os respondentes tomando as decisões quanto à compra de insumos e venda da produção, a maioria (9) das áreas com duas ou mais atividades agrícolas; na quase totalidade (11) delas, se cria pelo menos uma espécie animal, todos utilizam menos de $30 \%$ de trabalho contratado, $67 \%$ afirmam que terão um sucessor na família, quase todos (11) obtêm mais da metade da sua renda da atividade agrícola e todos têm propriedades entre 7 e 56 ha, havendo predominância (9) de áreas entre 7 e 14 ha. É importante ressaltar que as seis propriedades sorteadas, que pertenciam ao assentamento rural existente na MTB, foram classificadas dentro deste grupo; isso é particularmente interessante quando sabemos que 27 das 106 propriedades formam o assentamento, $25,5 \%$ portanto.
O grupo 2, formado por seis propriedades, se caracteriza por ter a maioria (5) dos respondentes tomando as decisões quanto à compra de insumos e venda da produção, a maioria (4) das áreas tem apenas uma atividade agrícola, na quase totalidade (5) delas não se cria nenhuma espécie animal, todos utilizam mais de $70 \%$ de trabalho contratado, $67 \%$ afirmam que não terão um sucessor na família e que obtêm mais da metade da renda da atividade agrícola, e todas as propriedades têm menos de 28 ha.

O grupo 3, formado por apenas quatro propriedades, se caracteriza por ter a maioria (3) dos respondentes tomando as decisões quanto à compra de insumos e venda da produção, a maioria (3) das áreas tem apenas uma atividade agrícola, na metade (2) delas não se cria nenhuma espécie animal, todos utilizam mais de $70 \%$ de trabalho contratado, metade afirma que não terá um sucessor na família, a maioria (3) afirma que obtém menos da metade da renda da atividade agrícola, e todas as propriedades têm mais de 56 ha.

TABELA 1. Número de propriedades, por categoria e proveniência da renda, na microbacia do Taquara Branca, Sumaré, SP. Maio de 1996.

\begin{tabular}{lccccc}
\hline Proveniência da renda & \multicolumn{5}{c}{ Categoria de renda } \\
\cline { 2 - 6 } & Nenhuma & Pouca & Metade & Muita & Total \\
\hline Plantação & 4 & 2 & 1 & 4 & 8 \\
Criação & 10 & 7 & 1 & 1 & 0 \\
Arrendamento & 18 & 1 & 0 & 0 & 0 \\
Salário & 17 & 0 & 1 & 1 & 0 \\
Outros & 10 & 5 & 1 & 3 & 0 \\
\hline
\end{tabular}

TABELA 2. Número de propriedades, por forma de posse e tipo de equipamento, na microbacia do Taquara Branca, em Sumaré, SP. Maio de 1996.

\begin{tabular}{|c|c|c|c|c|c|}
\hline \multirow{2}{*}{$\begin{array}{l}\text { Forma de posse do } \\
\text { equipamento }\end{array}$} & \multicolumn{5}{|c|}{ Tipo de equipamento } \\
\hline & Irrigação & $\begin{array}{c}\text { Pulverizador } \\
\text { manual }\end{array}$ & $\begin{array}{l}\text { Pulverizador } \\
\text { motorizado }\end{array}$ & $\begin{array}{l}\text { Pulverizador } \\
\text { tratorizado }\end{array}$ & Trator \\
\hline Próprio & 10 & 10 & 2 & 9 & 11 \\
\hline Alugado & 1 & 0 & 0 & 1 & 4 \\
\hline Outros & 4 & 1 & 0 & 3 & 1 \\
\hline
\end{tabular}




\section{CONCLUSÕES}

1. A agricultura familiar é a categoria individualmente mais freqüente na MTB, embora não seja predominante.

2. O questionário utilizado é de aplicação fácil e rápida, e permite coletar informação suficiente para a identificação de grupos de unidades de produção similares.

3. O método quantitativo utilizado na análise das respostas aos questionários se mostra adequado às necessidades de estudos dessa natureza e similares.

4. A facilidade encontrada tanto na aplicação como na análise e interpretação das respostas aos questionários, permite recomendar o método aqui utilizado para a fase inicial de aquisição de dados em trabalhos similares.

5. A possibilidade de incluir aspectos quantitativos às análises qualitativas geralmente adotadas nessa etapa dos trabalhos, auxilia a compreensão e fornece bases mais consistentes para as conclusões sobre os sistemas observados.

6. A análise multidimensional equaciona de maneira satisfatória o problema de tratar simultaneamente diversas variáveis, situação que é praticamente constante nos estudos ambientais.

\section{AGRADECIMENTOS}

Ao técnico especializado da Embrapa-CNPMA, agrônomo José Abrahão Haddad Galvão, e aos estagiários Alberto Paulo Vasquez, Gustavo Henrique Martinez e Marlene Borges, pelo auxílio na aplicação dos questionários.

\section{REFERÊNCIAS}

ANGELO, H.; RODRIGUEZ CASTRO, L.H.; PAULA, R.C. de. Aspectos sociais e econômicos da indústria madeireira no Distrito Federal. Revista de Economia e Sociologia Rural, Brasília, v.28, n.3, p.35-44, jul./set. 1990.

BAZIN, F. Viabilidade econômica dos assentamentos de reforma agrária - o caso de Sumaré, SP. Revista de Economia e Sociologia Rural, Brasília, v.32, n.2, p.123-144, abr./jun. 1994.
BUSCH, L.; BONANNO, A.; LACY, W.B. Science, technology, and the restructuring of agriculture. Sociologia Ruralis, Assen, v.29, n.2, p.118-130, 1989.

BUTTEL, F.H. Twentieth century agriculturalenvironmental transitions: a preliminary analysis. In: SCHWARZWELLER, H.K.; LYSON, T.A. (Eds.). Sustaining agriculture and rural communities. Greenwich : Jai, 1995. p.1-21. (Research in Rural Sociology and Development, 6).

CANUTO, J.C.; SILVEIRA, M.A. da; MARQUES, J.F Sentido da agricultura familiar para o futuro da agroecologia. Ciência \& Ambiente, Santa Maria, v.5, n.9, p.57-63, jul./dez. 1994.

CETESB. Acompanhamento da qualidade de água da represa de Sumaré: relatório parcial - nov. 1989 . jul. 1990. São Paulo : CETESB, 1991. 25p.

FAO (Roma, Itália). Diretrizes de política agrária e desenvolvimento sustentável para a pequena produção familiar: versão preliminar. Brasília : FAO/ INCRA, 1994. 98p. (Projeto UTF/BRA/036/BRA).

GASTAL, M.L.; ZOBY, J.L.F.; PANIAGO JÚNIOR, E.; MARZIN, J.; XAVIER, J.H.V.; SOUZA, G.L.C. de; PEREIRA, E.A.; KALMS, J.M.; BONNAL, P. Proposta metodológica de transferência de tecnologia para promover o desenvolvimento. Planaltina : Embrapa-CPAC, 1993. 34p. (EmbrapaCPAC. Documentos, 51).

JUDEZ ASENSIO, L. Técnicas de análisis de datos multidimensionales: bases teóricas y aplicaciones en agricultura. Madrid : Ministerio de Agricultura Pesca y Alimentación, 1988. 301p.

KAGEYAMA, A.; BERGAMASCO, S.M.P. Família e trabalho rural no Estado de São Paulo. [S.1.] : APIPSA, 1991. 26p. Trabalho apresentado no III Encontro Regional da APIPSA, Marília, SP, 1991.

KITAMURA, P.C.; SILVEIRA, M.A.; FERRÁZ, J.M.G.; BUSCHINELLI, C.C.A.; CASTRO, V.L.S.S.; CHAIM, A.; CORRALES, F.M.; MIRANDA, J.I. Diagnóstico agro-ambiental da microbacia hidrográfica do Taquara Branca - Sumaré, SP. Jaguariúna : Embrapa-CNPMA, 1999. 25p. (Embrapa-CNPMA. Documentos, 17)

LAL, R. Methods and guidelines for assessing sustainable use of soil and water resources in the tropics. Columbus : The Ohio State University, Department of Agronomy, 1994. 77p. (SMSS Technical Monograph, 21). 
LAMARCHE, H. (Coord.). A agricultura familiar: comparação internacional. Campinas : UNICAMP, 1993. $336 \mathrm{p}$.

LORENA, C. Aspectos da estrutura agrária brasileira. Reforma Agrária, Campinas, v.18, n.3, p.42-59, 1989.

MARTINE, G. Fases e faces da modernização agrícola brasileira. Brasília : IPLAN/São Paulo : IEA, 1989. 70p. (Texto para Discussão, 15).

MOLINA FILHO, J. Classificação e caracterização sócioeconômica dos agricultores. Revista de Economia Rural, Brasília, v.14, n.1, p.175-212, 1976.

MUNGUIA PAYÉS, M.A.; SILVEIRA, M.A. da. A racionalidade econômica do empresário familiar. Jaguariúna : Embrapa-CNPMA, 1997. 20p. (Embrapa-CNPMA. Documentos, 10).

MUSSOI, E.M. Agricultura familiar... agricultura "insuficiente"? Agropecuária Catarinense, Florianópolis, v.10, n.3, p.59, 1997.

OTANI, M.N.; CARRIERI, A. de P.; ANGELO, J.A. Microbacia - piloto do córrego de São Joaquim, DIRA de Campinas, Estado de São Paulo: um estudo comparativo 1988-94. Informações Econômicas, São Paulo, v.26, n.1, p.47-60, jan. 1996.

OTANI, M.N.; CARRIERI, A. de P.; ANGELO, J.A.; OLIVEIRA, S.J. de M.; OKAWA, H. Diagnóstico socioeconômico de MBHs: DIRA de Campinas. Informações Econômicas, São Paulo, v.25, n.3, p.5568, mar. 1995

PINHEIRO, S.L.G. O papel do enfoque sistêmico nas ações de pesquisa e extensão rural voltadas a agricultura familiar. Agropecuária Catarinense, Florianópolis, v.5, n.4, p.19-21, dez. 1992.

REINHARDT, N.; BARLETT, P. The persistence of family farms in United States agriculture. Sociologia Ruralis, Assen, v.29, n.3/4, p.203-225, 1989.
SAMPAIO, P. de A. A reforma agrária. Reforma Agrária, Campinas, v.18, n.2, p.5-13, ago./nov. 1988.

SANTANA, A.C. de; KHAN, A.S. Análise sócio-econômica de pequenas unidades de produção em Santa Izabel do Pará. Revista de Economia e Sociologia Rural, Brasília, v.28, n.2, p.255-274, abr./jun. 1990.

SAS INSTITUTE. SAS procedures guide, release $\mathbf{6 . 0 3}$ Cary, NC, 1988. 441p.

SILVA, J.G. da. (Coord.). Diferenciação camponesa e mudança tecnológica: o caso dos produtores de feijão em São Paulo. Campinas : UNICAMP, 1982. $42 \mathrm{p}$.

SILVA, J.G. da. Sobre a delimitação do rural e do urbano no Brasil: testando as aberturas geográficas das novas PNADs. In: CONGRESSO ANUAL DA SOBER, 35., 1997, Natal, RN. Anais. Natal : SOBER, 1997. p.114-146.

SILVEIRA, M.A. da. Agricultura familiar e a questão ambiental: contribuições metodológicas para o enfoque participativo. In: SEMINÁRIO DE METODOLOGIA DE PROJETOS DE EXTENSÃO, 2., 1998, Rio de Janeiro, RJ. Extensão universitária e metodologia participativa. Rio de Janeiro : COPPE/UFRJ, 1998a. p. 43-50.

SILVEIRA, M.A. da. Desenvolvimento rural sustentável em um assentamento: análise e intervenção participativa. Raízes: Revista de Ciências Sociais e Econômicas, Campina Grande, v.17, n.16, p.100-112, mar. 1998b.

SOUZA NETO, J. de; BAKER, G.; SOUSA, F.B. de. Análise socioeconômica da exploração de caprinos e ovinos no Estado do Piauí. Pesquisa Agropecuária Brasileira, Brasília, v.30, n.8, p.1017-1030, ago. 1995.

VEIGA, J.E. da. O desenvolvimento agrícola: uma visão histórica. São Paulo : Edusp/HUCITEC, 1991. $219 \mathrm{p}$. 